\title{
Morte e conflitos sociais na Jamaica escravista
}

\section{Cláudia Rodrigues}

BROWN, Vincent. The Reaper's Garden: Death and Power in the World of Atlantic Slavery. Massachusetts/ London: Harvard University Press, 2008.

Até que ponto a morte e seus significados podem ser centrais tanto para a manutenção da ordem como para os conflitos sociais? Em Reaper's Garden, Vincent Brown consegue demonstrar esta possibilidade. Segundo ele, os indivíduos atribuem profundo significado político às crenças e práticas associadas à morte, relacionando-as a disputas por objetivos específicos, no que denominou de política mortuária. O autor parte da constatação de que as altas taxas de mortalidade têm sido amplamente reconhecidas - e Brown se dá ao direito de não apresentá-las - como um dos fatores mais marcantes das sociedades escravistas coloniais e que pouco se sabe sobre suas implicações sociais e políticas. Diante disto, propõe-se a investigar de que forma a morte moldou o cotidiano em sociedades escravistas e como a população simbolizou as atitudes diante da morte em disputas por autoridade, moralidade, memória, propriedade, território e pertences.

Para desenvolver sua argumentação, analisa o caso da Jamaica no período escravista - a colônia mais importante do Império britânico - entre o século XVIII e o início do XIX. Apresentando altos índices de mortalidade, era reconhecida na época como o "cemitério dos europeus". O autor se debruça, então, sobre o cenário ideal para uma análise que associa morte, poder e escravidão, demonstrando no Capítulo I (World of wealth and death) que a onipresença da morte abrangia todos os segmentos sociais, determinando a constante reposição tanto de cativos - através do lucrativo tráfico atlântico -, como de europeus - por meio do constante fluxo migratório em busca de fortuna e enriquecimento rápido. Apesar de seu domínio universal naquela sociedade, podemos observar no segundo capítulo (Last rites and first principles) que a morte não igualava, sendo os ritos fúnebres um dos caminhos através dos quais as fronteiras e as relações de pertença grupais, as hierarquias sociais e a riqueza se manifestavam - não só entre negros e "brancos", mas também no interior de cada um destes grupos -, potencializando conflitos.

Através de uma narrativa fluente, empiricamente embasada, sensível e politicamente engajada - o que não prejudica a leitura em nenhum momento -, Brown demonstra ao longo de sete capítulos que as atitudes diante da morte afetaram intensamente a história dos vivos na Jamaica escravista. E este é justamente um dos motivos pelos quais o texto prende a atenção do leitor. Por diferentes e inusitados caminhos, o autor consegue expor características essenciais àquela sociedade: de que modo os indivíduos formularam suas relações com os mortos; como crenças e práticas mortuárias responderam a mudanças demográficas, socioeconômicas, políticas e religiosas; de que maneira as relaçôes com os mortos estiveram embutidas em conflitos políticos; e como as políticas mortuárias moldaram o curso da história jamaicana - e por que não, do próprio Império britânico -, haja vista que as relações com os mortos se fizeram presentes em conflitos, rebeliōes e até mesmo na política parlamentar. Sobre este aspecto, por exemplo, o Capítulo V (The soul of the Britsh Empire) examina como as mortes violentas de escravos - em especial, o caso Zong, em 1781, quando o capitão de um navio negreiro resolveu lançar ao mar os africanos doentes e fracos, diante de uma epidemia, para não depreciar a "carga" - influenciaram daí por diante o desenvolvimento do movimento antiescravista entre os britânicos. Servindo de instrumento retórico aos abolicionistas, o caso e a temática da morte potencializaram as lutas pelo fim do tráfico atlântico (1807) e pela abolição da escravidão (1838), tendo sido usados de diferentes formas enquanto eficazes símbolos das críticas abolicionistas à "decadência moral" daquele Império escravista. Mas, interessante também é constatar que a mortalidade escrava se transformou no campo temático no interior do qual não só os abolicionistas, mas também os escravistas procuraram defender seus pontos de vista. 
Em termos metodológicos, Brown fez um bom uso de variadas fontes discursivas, que lhe pareceram díspares e fragmentadas, mas que justamente por isso conferiram riqueza à sua análise. Através de uma meticulosa pesquisa no rico acervo documental sobre a Jamaica escravista - diários, relatos de viajantes, crônicas, apontamentos paroquiais, registros das fazendas, atas parlamentares, imagens, autobiografias de ex-escravos, literatura, transcrições tumulares, testamentos etc. - , o autor conseguiu identificar as mais diretas e indiretas referências à morte, aos mortos e às visões sobre o além-túmulo entre os livres e, principalmente, entre os cativos. Neste sentido, o belo Capítulo IV (Icons, shamans and martyrs) demonstra de que forma senhores e escravos tentaram apoiar sua autoridade na Jamaica tendo como base uma conexão com o transcendental, conferindo significado sobrenatural a assuntos do mundo terreno. $\mathrm{Na}$ tentativa de controlar as práticas de suicídio entre os cativos - utilizadas como um recurso para escapar da escravidão e reencontrar os ancestrais -, proprietários de escravos aterrorizavam-nos por meio de mutilações e da exposição pública de partes dos cadáveres para demonstrar que os suicidas não haviam "retornado" para a África, como se acreditava, uma vez que suas cabeças estavam ali expostas. Com isso, os senhores tentavam disseminar a ideia de punição vingativa aos espíritos dos cadáveres de rebeldes e suicidas. Em contraposição, Brown demonstra como a tradicional crença nos espíritos levava os escravos a fazer uso dos mortos a seu favor, provocando a autoridade política e senhorial, recorrendo a práticas xamânicas no contato com o mundo dos mortos, para obter a proteção para revoltosos, bem como controlar as forças consideradas malévolas dos espíritos errantes que pudessem causar desarmonia à comunidade cativa.

Um dos méritos da obra de Brown é a forma como se insere teoricamente no conjunto dos trabalhos produzidos acerca da escravidão atlântica. Situando-se na esteira das pesquisas que seguiram a advertência de Sydney Mintz e Richard Price (The birth of African-American culture, 1976) sobre a necessidade de se examinar cuidadosamente as formas pelas quais a vida material moldou a evolução das crenças e práticas que os africanos trouxe- ram para a América, Brown enfatiza a criatividade cultural dos escravizados. Assim, no Capítulo VI (Holy ghosts and eternal salvation) analisa como a adaptação do cristianismo também se fez segundo os interesses básicos dos negros na associação da morte e dos espíritos às tensões políticas da escravidão. A mensagem cristã de igualdade no além, transposta para a esfera terrena (devido à forte vinculação que os africanos estabeleciam entre mundo espiritual e o imanente), associava os horrores da escravidão aos temores do Inferno. $\mathrm{O}$ cristianismo, portanto, foi utilizado como poderosa arma para o movimento por reformas políticas, ao ponto de convertidos ao protestantismo terem se tornado importantes líderes na luta contra a escravidão. Brown examina a oposição de proprietários e missionários aos rituais funerários africanos por se constituírem em ocasião para o ajuntamento de centenas de escravos à noite, distantes do olhar senhorial, possibilitando-lhes a articulação de revoltas. Aos missionários evangélicos, tais práticas repugnavam por apresentarem rituais e concepções divergentes das cristãs, tais como as práticas divinatórias sobre caixões, as inquirições espirituais aos mortos, os sacrifícios de animais e as oferendas sobre as sepulturas. Daí, as tentativas de intervenção política e religiosa que seriam conduzidas no processo de conversão, mas que nem sempre foram controladas pelas autoridades.

Procurando ir além de uma história cultural da identidade, Brown demonstra que as práticas culturais, em especial as relacionadas à morte, representaram um significativo papel na história política da escravidão. Ele, de fato, consegue convencer o leitor de que as relaçôes dos vivos com a morte e os mortos transformaram o transcendental em instrumento para conflitos terrenos. Três exemplos são significativos.

No Capítulo III (Expectations of the death), ao analisar as expectativas de brancos e negros em torno da morte, destaca que se tratava de uma ocasião para se (re)afirmar fortunas e posição social através dos legados. Se os brancos buscavam perpetuar suas linhagens por meio da transmissão de heranças, os cativos também o faziam. Apesar dos limites jurídicos impostos pela sociedade escravista - proibição da redação de testamentos cartorários aos cativos -, a morte proporcio- 
nava ganhos para alguns escravos: pela obtenção da alforria e de recursos financeiros, após o falecimento dos senhores, ou pelo recebimento de legados de companheiros e parentes cativos que tivessem acumulado com a venda dos produtos de sua roça. Neste ponto, Brown apresenta uma bela análise de como alguns escravos conseguiram transmitir, oralmente e em "testamentos" anotados pelos senhores, seus pertences e roças, envolvendo negociações e conflitos pela posse de lotes de terra. No Capítulo VII (Gardens of remembrance) descreve, com primor, como os rebeldes usurparam o improvisado caixão de um membro das tropas escravistas para sepultar o cadáver de um coronel negro envolvido na Guerra Batista, em 1831, considerada a maior rebelião negra a ameaçar a colônia britânica, e que precipitou a abolição da escravidão, sete anos mais tarde. No mesmo capítulo, Brown destaca a mobilização de memórias individuais e coletivas - tanto por escravos, quanto por livres - no sentido de que os feitos dos mortos fossem empregados para legitimar disputas, durante e após a escravidão. São exemplos os monumentos funerários, como instrumentos de perpetuação de uma determinada versão sobre os conflitos entre proprietários e escravos (apresentando os senhores mortos como mártires e benfeitores daquela sociedade) e, do lado dos cativos, a reverência aos locais de sepultura dos entes queridos e a insistência em permanecer próximo a eles, recusando-se a abandonar seus lotes e casas. De uma sensibilidade ímpar e, ao mesmo tempo, convincente historicamente, este último capítulo também nos mostra, por um lado, como os negros usaram os rituais fúnebres para literalmente enterrar a escravidão no dia marcado para a sua extinção, construindo túmulos e epitáfios para ela, e por outro, analisa os processos de afirmação e de esquecimento da memória, ao examinar os diferentes significados e destinos dados às sepulturas de um importante membro da elite jamaicana, de um missionário antiescravista e de um rebelde negro.

Mas, a forma como Brown tece seus argumentos também nos leva a cogitar se sua análise não poderia ter avançado. Um caminho seria a interlocução com o trabalho de James Sweet (Recreating África, 2003) - que defende que os negros mantiveram a essência africana nas Américas, a exem- plo das concepções acerca da morte e dos mortos que Brown apenas cita rapidamente no Epílogo. É fato que no Capítulo VI, diferentemente de Sweet, Brown defende a ideia de uma "crioulização do mundo espiritual", ao analisar o processo de conversão de escravos ao cristianismo e a utilização da morte para transformar as tradicionais crenças africanas nos espíritos e no poder dos mortos. Para isso, recorre a John Thornton e a sua tese acerca do cristianismo africano (Africa and Africans in the making of the Atlantic world, 1992) para investigar o processo de incorporação do cristianismo pelos negros, no contexto das transformaçõos sociais, demográficas e políticas das primeiras décadas do século XIX. Mas, ainda assim, poderia ter oferecido ao leitor interessado na diáspora africana no Novo Mundo e nas atitudes africanas diante da morte uma excelente oportunidade para acompanhar a discussão sobre a transposição das crenças africanas - a exemplo da persistente crença nos espíritos dos mortos - para a América, no contexto da complexa conversão ao cristianismo. O diálogo com Sweet, portanto, poderia ressaltar divergências e aproximações entre duas análises recentes que enfocam o grande significado dos mortos, dos espíritos e dos ancestrais para africanos e seus descendentes, no bojo das análises sobre o processo de transformações culturais dos africanos nas Américas. Seria, também, uma excelente oportunidade para situar tais abordagens no já clássico debate iniciado por Mintz e Price acerca da criolização da cultura negra.

Esta ausência, no entanto, não tira o mérito do trabalho de Brown, que nos convence da viabilidade de se pensar a política mortuária vivenciada na Jamaica escravista como lócus de análise para as implicações políticas das práticas culturais e como o autor muito bem defende - para uma história material do imaginário sobrenatural. Além disso, em vários momentos, o autor nos brinda com instigantes reflexões sobre as concepções e atitudes diante da morte no século XVIII, principalmente as de matriz protestante - pouco investigadas -, lançando luz também sobre a história da morte no Ocidente e não apenas sobre a história social e cultural da escravidão e da diáspora africana na Época Moderna. Por todos estes motivos, Reaper's Garden é um livro que não se pode deixar de ler e que, oxalá, venha a ser traduzido. 